\title{
G7 ülkelerinin bilgi performanslarının analizi: COCOSO yöntemi ile bir uygulama
}

\section{Analysis of knowledge performance of $G 7$ countries: An application with the COCOSO method}

\section{Furkan Fahri Altıntaş}

Dr., Jandarma Genel Komutanlığ1 - Yönetici, TÜRKIYY, e-mail: furkanfahrialtintas@yahoo.com

$\ddot{O} z$

Bu araştırmada, G7 ülkelerinin en son ve güncel olan 2020 yılı Küresel Bilgi Endeksi (GKI) bileşenlerine ait değerler üzerinden ülkelerin bilgi performansları COCOSO yöntemi ile ölçülmüştür. Araştırmada ayrıca GKI ve COCOSO yöntemi kapsamında tespit edilen performans değerleri ile bazı çok kriterli karar verme yöntemleri (ÇKKV: EDAS, TOPSIS ve GIA) ile tespit edilen ülkelerin bilgi performans değerleri arasındaki uyum durumu belirlenmiştir. Bulgulara göre, bilgi performans ortalama değerinin üstünde olan ülkelerin $A B D$ ve İngiltere olduğu tespit edilmiştir. Bu kapsamda ortalama değerin altında kalan Japonya, Kanada, Almanya, İtalya ve Fransa ülkelerinin diğger G7 grubu ülkeleri ile bilgi performansı açısından uyum sağlaması için Küresel Bilgi Endeksi bileşenlerine gerekli önemi vermeleri gerektiği sonucuna ulaşılmıştır. Diğer bir bulguya göre, GKI ve COCOSO yöntemlerinin birbirleri ve diğer ÇKKV yöntemleri ile uyum içinde olduğu gözlenmiştir.

Anahtar kelimeler: bilgi, küresel bilgi endeksi, COCOSO

Jel kodlarn: D83, C44, H11

\section{Abstract}

In this research, the knowledge performance of the G7 countries was measured by the COCOSO method over the values of the latest and up-to-date Global Konwledge Index (GKI) components of the 2020 year. In the study, the harmony between the performance values determined within the scope of GKI and COCOSO methods and some multi-criteria decision making methods (MCDM:, EDAS, TOPSIS, and GIA) were determined. According to the findings, it has been determined that the countries with higher information performance average values are the USA and the England. In this context, it has been concluded that the countries of Japan, Canada, Germany, Italy and France, which are below the average value, should give the necessary importance to the components of the Global Knowledge Index in order to harmonize with other G7 group countries in terms of knowledge performance. According to another finding, it was observed that the GKI and COCOSO methods were in consistence with each other and with other MCDM methods.

Keywords: knowledge, global knowledge index, COCOSO

Jel codes: D83, C44, H11 


\section{Gíriş}

Bilginin temel nitelikli bir yapısı bulunmakta olup, bilgi ile ilgili olarak literatürde pek çok araştırma bulunmaktadır. Bu kapsamda Buckland (1991) bilgiyi k1saca enformasyon bütünü olarak tanımlamıştır. Bhatt (2001) ise Buckland (1991)'ın tanımını biraz daha detaylandırarak bilgiyi zihinlerin ve tecrübelerin bileşimiyle hedefe veya hedeflere odaklanan anlamlı enformasyon bütünü olarak açıklamıştır. Durna ve Demirel (2008) ise bilgiyi belirli tecrübe değerlerinin amaca yönelik olan enformasyonun ve uzmanlık görüşünün farklı ve yeni tecrübe ve enformasyonla bir araya gelmesi ile oluşan esnek bir bileşen olarak belirtmiştir.

Bilgi, veri ve enformasyon olmak üzere iki unsurdan oluşmaktadır. Söz konusu veri ve enformasyonun kaynaşması ile bilgi oluşmaktadır. Veriler içeriği olmayan ve üzerinden yorum sağlanamayan ham oluşumlardır (Hariharan ve Kheneja, 2003). Enformasyon ise bir mesaj özelliği taşımakta olup, verilerin anlam kazanmasına aracı olan bir yapı özelliği taşımaktadır (Davenport ve Prusak, 2001). Özetle veri henüz yorumlanmayan basit gözlemleri, enformasyon işlenmiş verileri ve son olarak bilgi ise enformasyonun kullanılabilirliğini içermektedir (Durna ve Demirel, 2008).

Sistematik bir düzen içinde ülkelerin her konu hakkında bilgi sahibi olmaları ülkelerin bilim, teknik, sanat, sağlık, spor, sosyal ve birçok boyutun gelişmesine katkıda bulunmuştur. Bu kapsamda ülkeler bilginin doğru zamanda, doğru yöntemle ve doğru yapılar ile kullanarak kendi gelişmelerini katmerleştirebilmektedirler. Çünkü ülkeler, bilgilerin kaynaşması ile farklı ve özgün yeni ve çeşitli bilgilere ulaşılarak bilginin sinerjik özelliğinden faydalanmak istemektedirler.

Bilginin önemi kapsamında ülkeler her zaman kendi bilgi performanslarını takip etmektedirler. Bu kapsamda ülkeler, kendi bilgi performanslarının farkındalığı ile bilgi performansı konusunda eksikliklerini gidermek ve bilgi yeterliliklerinin sürdürülebilirliğini sağlamak için mevcut ve sonraki dönemler için stratejiler, yöntemler, yönetimler ve faaliyetler gerçekleştirebilmektedirler. Ayrıca ülkeler, birbirlerinin bilgi performanslarını da takip etmektedirler. Çünkü ülkeler, bilgi performansı iyi olan ülkeler ile bilgi edinimi için iş birlikleri ve ortaklıklar sağlayabilmektedirler. Dolayısıyla ülkeler kendi bilgi performanslarını uluslararası alanda ölçen metriklere, ölçeklere veya endekslere her zaman gereksinim duymaktadırlar.

Ülkelerin uluslararası alanda bilgi performanslarını ölçen metriklerden biri Küresel Bilgi Endeksi (Global Knowledge Index - GKI'dir. GKI ile ülkelerin bilgi performanslarının ölçümü ilk olarak Birleşmiş Milletler Kalkınma Programı (United Nations Development Programme) ve Mohammed bin Rashid Maktaum Bilgi Vakfı (MBRF) arasında ortak bir girişimle 2017 yılında sağlanmıştır (UNDP ve MBRF, 2017). Söz konusu endeks ile ülkelerin çok boyutlu olarak bilgi performanslarını ölçmek amaçlanmıştır. Bunun yanında GKI genel anlamda bilgi ekonomisi ve bilgi toplumu ile ilişkilidir (UN ve MBRF, 2018). Bu sebeple GKI ile ülkelerin ekonomik ve sosyal yapılar ile ilişkili olan birçok boyutun analizi yapılabilmektedir. Bu durum GKI'nın bilgi politikalarının daha anlamlı olmasına ve daha derinlemesine yönelik incelenmesine olanak sağlamaktadır (UN ve MBRF, 2018). Ayrıca GKI, 2015 yılında dünya liderleri tarafından kabul edilen 2030 sürdürülebilir kalkınma kavramının devamlılığının sağlanmasında kalkınma ile bilgi arasında bilimsel bir kanıt sunmaktadır. Bunların dışında GKI politikacılara, araştırmacılara, sivil toplum kuruluşlarına ve özel sektörlere bilgiye dayalı toplumları keşfetmek ve bilgi boşluklarını kapatmak adına rehberlik ve bilgilendirme sağlamaktadır (UN ve MBRF, 2020).

GKI 7 bileşen, 7 bileşene bağlı 17 değişken ve 17 değişkene bağlı 133 alt değişkenden oluşmaktadır. Alt değişkenlerin aritmetik ortalamalarıyla değişkenler,

Tablo 1. GKI Bileşenleri, Bileşen Ağırlıkları ve Bileşenlere Bağlı Değişkenler

\begin{tabular}{|c|c|c|}
\hline Bileşenler & Ağırlıklar & Değişkenler \\
\hline \multirow{2}{*}{ Üniversite Öncesi Eğitim } & \multirow{2}{*}{$15 \%$} & Bilgi Sermayesi \\
\hline & & Eğitime Olanak Sağlayan Ortam \\
\hline \multirow{2}{*}{ Teknik ve Mesleki Eğitim ve Öğretim } & \multirow{2}{*}{$15 \%$} & Mesleki Eğitim \\
\hline & & İşgücü Piyasası \\
\hline \multirow{2}{*}{ Yüksek Öğretim } & \multirow{2}{*}{$15 \%$} & Yüksek Öğretim Girdileri \\
\hline & & Yüksek Öğretim Çıktıları \\
\hline \multirow{3}{*}{ Araştırma, Geliştirme ve Yenilik } & \multirow{3}{*}{$15 \%$} & AR-GE \\
\hline & & Üretimde İnovasyon \\
\hline & & Sosyal İnovasyon \\
\hline \multirow{2}{*}{ Bilgi ve İletişim Teknolojisi } & \multirow{2}{*}{$15 \%$} & Bilgi ve İletişim Teknolojisi Girdileri \\
\hline & & Bilgi ve İletişim Teknolojisi Çıktıları \\
\hline \multirow{3}{*}{ Bilgi Ekonomisi } & \multirow{3}{*}{$15 \%$} & Bilgi Rekabet Gücü \\
\hline & & Ekonomik Açıklık \\
\hline & & Finansman ve Katma Değer \\
\hline \multirow{3}{*}{ Genel Etkinleştirici Ortam } & \multirow{3}{*}{$10 \%$} & Politik ve Kurumsal \\
\hline & & Sosyo-Ekonomik \\
\hline & & Sağlık ve Çevre \\
\hline
\end{tabular}

GKI bileşenlerin açıklamaları ise aşağıda maddeler halinde açıklanmıştır (UNDP ve MBRF, 2020). 
değişkenlerin aritmetik ortalamaları ile GKI bileşen değerleri hesaplanabilmektedir. Sonrasında her bir bileşeninin ağırlık katsayısı ile ülkelerin GKI değerleri tespit edilebilmektedir (UN ve MBRF, 2020). Buna bağlı olarak GKI'nın bileşenleri, bileşen ağırlıkları ve değişkenleri Tablo 1'de gösterilmiştir.

Üniversite Öncesi Eğitim: Gençleri bilgi edinmeye ve üretmeye hazırlamada ve bilgi sermayesinin oluşturulmasında merkezi bir rol oynar. Üniversite öncesi eğitim, gençleri yaşam boyu öğrenme fırsatlarına erişmeleri için bilimsel bilginin yanı sıra yaratıcı beceriler ve kapasitelerle donatır. Bu bileşen bu nedenle diğer bileşenlerin üzerine inşa edeceği ilk temeli oluşturduğu için anahtar niteliği taşımaktadır

Teknik ve Mesleki Eğitim ve Öğretim: Teknik ve mesleki eğitim ve öğretim, eğitim ile işgücü piyasası arasındaki ana bağlantıyı temsil eder ve eğitimli gençlere profesyonel bütünleşme firsatları sağlar. Ayrıca teknik ve mesleki eğitim ve öğretim, yüksek vasıflı işgücünün sağlanmasına ve elverişli çalışma ortamlarının geliştirilmesine katkıda bulunur.

Yüksek Öğretim: Yüksek öğretim, gençlerin eğitilmesinde, niteliklerinin geliştirilmesinde ve bilgi ve becerilerinin genişletilmesinde aktif bir bileşen olduğundan ve bir ülkenin üretkenliğinin küresel pazarlarda rekabet gücünün artmasına katkıda bulunduğundan büyük önem taşımaktadır. Ayrıca yüksek öğretim, bilimsel araştırma ve teknolojik gelişmenin ilerlemesine doğrudan sağlayan en önemli faktörler arasında kabul edilmektedir.

Araştırma, Geliştirme ve Yenilik: Araştırma, geliştirme ve yenilik, ulusal ve bölgesel düzeylerde bilginin artmasına katkıda bulunur. Hem gelişmiş hem de gelişmekte olan ülkelerde ekonomik büyüme ve sürdürülebilir kalkınma için bir itici güç olarak araştırmaya, geliştirmeye, yeniliğe ve yeni veya geliştirilmiş malların, hizmetlerin, üretim süreçlerinin ve organizasyon modellerinin üretimine dayanmaktadır. Araştırma, geliştirme ve yenilik, tüm sisteme temel girdiler sağladığı için diğer bileşenler ile yakından ilişkilidir.

Bilgi ve İletişim Teknolojisi: Bilgi ve iletişim teknolojisi, tüm bileşenlerde bilginin ilerlemesini desteklemede önemli bir rol oynar. Bilgi yoğun üretimdeki gelişmeler, özellikle internet ile bilgi edinme fırsatlarını ve ileri teknolojinin birbirleri ile ilişkili olmasını sağlamaktadır. Bu nedenle, ülkelerin kendi toplumlarındaki paydaşların yararı için bilgi ve iletişim teknolojisi geliştirme seviyelerini ölçen göstergeleri kullanmaları çok önemlidir.

Bilgi Ekonomisi: Bilgi ekonomisi, endüstriyel, tarım ve hizmet sektörlerinde çeşitli ekonomik alanlarda sürdürülebilir kalkınmanın, zenginlik ve iş yaratmanın ana itici gücüdür. Bilgi ekonomisi, bilgi ekonomisinin temeli olan ekonomik ve insan kaynaklarına, dijital ve teknolojik bilgi varlıklarına, bilgi araçlarına ve yenilikçi ve yaratıcı becerilerin sağlamasına dayanmaktadır.

Genel Etkinleştirici Ortam: Genel etkinleştirici ortam, 6 bileşeni desteklemek için eklenmiştir. Çünkü bu bileşenler çevrelerinden izole olarak değil, bir dizi bağlamsal faktör tarafından yönetilen bir alanda faaliyet göstermektedirler.

Araştırmada bilgi gücünü ekonomik güce çeviren G7 gurubu ülkelerin bilgi performansları COCOSO yöntemi ile ölçülmüştür. Devamında söz konusu ülkelerin GKI ve COCOSO yöntemi kapsaminda elde edilen bilgi performans değerleriyle bazı ÇKKV yöntemleri kapsamında elde edilen performans değerleri arasında ilişki değerleri tespit edilerek özellikle GKI'nın ve COCOSO yönteminin birbirleri ve diğer ÇKKV yöntemler ile olan uyum durumları belirlenmiştir. Literatür değerlendirildiğinde, ülkelerin bilgi performanslarını herhangi bir ÇKKV yöntemi ile ölçen bir araştırmaya rastlanılmamıştır. Bu kapsamda araştırmada elde edilen bulgular gelecek çalışmalar için bir veri seti niteliği taşımaktadır. Ayrıca Türk literatüründe COCOSO yöntemi ile karar alternatiflerinin performanslarını ölçen herhangi bir araştırmaya rastlanılmaması açısından bu araştırmanın literatüre katkı sağladığı değerlendirilmiştir. Bu kapsamda araştırmanın literatür kısmında bilgi disiplinleri ile COSOSO yöntemi ile ilgili olarak araştırmalar açıklanmıştır. Araştırmanın yöntem bölümünde ise araştırmanın amaçları, analiz düzeyi ve COCOSO yöntemi belirtilmiştir. Son olarak araștırmanın sonuç bölümünde ise bulgular kapsamında sağlanan nicel değerlere istinaden çıkarımlar sağlanıp tartışılmıştır.

\section{LITERATÜR TARAMASI}

Araştırmanın literatürü iki kısımdan oluşmaktadır. Bunlardan birincisinde bilgi ile ilgili araştırmalar belirtilmiştir. İkincisinde ise ENTROPI ve COCOSO yöntemi ile ilgili araştırmalar açıklanmıştır.

Literatürde bilgi kavramını konu alan pek çok çalışma bulunmaktadır. Bilginin tüm bilim dallarının temel yapısını oluşturması, literatürde bilgi ile ilgili araştırmalarının çok olmasının doğal sebebidir. Literatür incelendiğinde, bilgi ile ilgili olan araştırmalarda bilgi boyutunun diğer boyut veya kavramlar ile birlikte kullanılarak bilgi kavramından türeyen farklı disiplinler üzerinde çalışmaların yoğunlaştığ 1 gözlenmiştir. Söz konusu bilgi disiplinleri ile ilgili bazı araştırmalar Tablo 2'de gösterilmiştir. 
Tablo 2. Bilgi Kavramı ile İlgili Literatür

\begin{tabular}{|l|l|}
\hline \multicolumn{1}{|c|}{ Bilgi Disiplinleri } & \multicolumn{1}{c|}{ Araştırmacılar } \\
\hline Bilgi Ekonomisi & $\begin{array}{l}\text { Doz vd. (2001), Peters (2003), Powell ve Snellman (2004), Bastalich (2010), Işık ve Kılınç (2013), } \\
\text { Hadad (2017), Timor ve Yüzbaşı Künç (2021) }\end{array}$ \\
\hline Bilgi Güvenliği & $\begin{array}{l}\text { Desouza (2006), Dauth vd. (2018), Jalali vd. (2021), Kılıç vd. (2020), Talan ve Aktürk (2021), Tang } \\
\text { vd. (2021), Wu vd. (2021) }\end{array}$ \\
\hline Bilgi Okuryazarlı̆̆ı & $\begin{array}{l}\text { Martin ve Rader (2004), Adı̈üzel (2011), Kurbanoğlu (2011), Mackey ve Jacobson (2011), Brady } \\
\text { (2021), Jones-Jang vd. (2021), Naveed (2021) }\end{array}$ \\
\hline Bilgi Sistemleri & $\begin{array}{l}\text { Demirhan (2002), Tengö vd. (2014), Anameriç (2005), Ingram (2018), Abu vd. (2020), Fokou ve } \\
\text { Fokouo (2020), Ubisi (2019) }\end{array}$ \\
\hline Bilgi Teknolojileri & $\begin{array}{l}\text { Alsayed ve Bilgirami (2017), Alam vd. (2020), Chatterjee vd. (2020), Kaya vd. (2020), Keleş ve } \\
\text { Ova (2020), Ugli (2020), Ye vd. (2020) }\end{array}$ \\
\hline Bilgi Toplumu & $\begin{array}{l}\text { Höhne (2003), Green (2006), Olimpio (2010), Etzkowitz vd. (2012), Ezer ve Kiral (2018), Güner } \\
\text { (2020) }\end{array}$ \\
\hline Bilgi Yönetimi & $\begin{array}{l}\text { Shokri-Ghasabeh ve Chileshe (2014), Durnalı ve Limon (2020), Özer vd. (2020), Bratianu vd. } \\
\text { (2021), Di Vaio vd. (2021), Hock-Doepgen vd. (2021), Wahab vd. (2021) }\end{array}$ \\
\hline
\end{tabular}

Literatürün ikinci kısmı kapsamında Yazdani ve diğg. (2018), Fransa'da lojistik faaliyeti yürüten işletmelerin ilgili değerleri üzerinde lojistik performanslarını COCOSO yöntemi ve bazı ÇKKV yöntemleri üzerinden karşılaştırmışlardır. Araştırma sonucunda, COCOSO yönteminin ile tespit edilen sıralamaların sadece WASPAS ile VIKOR yöntemleri ile sıralama tutarlılığ1 sağladığı tespit edilmiştir. Barua ve diğ. (2019), hibrit doğal elyaf takviyeli NONOSIC parçacıkların mekanik özelliklerinin performanslarını Taguchi ve COCOSO yöntemi ile belirlemişlerdir. Araştırma sonucuna göre, yoğunluk ve eğilme dayanımlarının NONOSIC parçacıklarının mekanik özelliklerini çok iyi yansıttığ1 tespit edilmiştir. Peng ve diğ. (2019), 5G endüstri şirketlerinin performanslarının belirlenmesini CRITIC tabanlı COCOSO yöntemi ile ölçmüşlerdir. Devamında araştırmacılar daha öncesinde aynı veriler ile 5G endüstri şirketlerinin performanslarının bazı CRITIC tabanlı ÇKKV yöntemleri ile (TOPSIS, TODIM, MABAC, GWFEWG, PFHPWA, PFHPWG, LPFWG, PFIWG, SPFWA) karşılaştırmışlardır. Araştırmada, CRITIC tabanlı COCOSO yönteminin CRITIC taban11 TOPSIS, TODIM ve MABAC yöntemleri arasındaki korelasyon değerleri anlamlı, pozitif yönde ve yüksek olmasından dolayı söz konusu yöntemlerin birbirleriyle uyumlu olduğu gözlenmiştir. Zolfani ve diğ. (2019), çelik endüstrisinde en iyi tedarikçi seçiminin belirlenmesinde BWM tabanlı COCOSO ile hibrid MADM yöntemleri ile bir model önermişlerdir. Araştırma kapsamında önerilen modelin karmaşık durumlarda sürdürülebilir sorunları çözmede etkili olduğu sonucuna ulaşılmıştır. Biswas (2020), Hindistan'da sağlık kurumlarının tedarik zinciri performanslarını PIPRECIA ağırlıklı MABAC, COCOSO ve MARCOS yöntemleri ile belirlemiştir. Araştırma sonucuna göre, her üç yönteme göre sağlık kurumlarının tedarik zinciri performanslarının sıralamalarının birbirlerine benzer olduğu ve söz konusu yöntemler arasında pozitif yönlü anlamlı ve yüksek ilişkiler olduğu gözlenmiştir. Ecer ve Pamucar (2020), tedarikçi seçim probleminin çözümüne yönelik BWM tabanlı Benferroni Bulanık COCOSO yöntemi ile bir model önerisinde bulunmuşlardır. Araştırma sonucuna göre, önerilen modelin belirsizlik içinde sürdürülebilir olduğu sonucuna ulaşılmıştır. Caudhary ve Mishra (2021), Endüstri 4'ün başarı sağlayıcılarının performanslarını bulanık AHP tabanlı COCOSO ve Yakınlık Endeks Yöntemi (PIV) ile hesaplamışlardır. Araştırmada her iki yöntem ile hesaplanan performans değerlerinin birbirlerine benzer olduğu tespit edilmiştir. Bagal ve diğ. (2021), endüstride kullanılan kaynak parametrelerin performanslarını COSOSO, WASPAS ve EDAS tabanlı Taguchi yöntemi ile ölçmüşlerdir. Araştırma sonucuna göre, en iyi performans sergileyen kaynak parametrelerin kaynak süresi ve akımı, çekme-kesme dayanıklılığ1 ve kaynak yapılan maddenin külçe çapının olduğu belirlenmiştir. Mishra ve diğ. (2021), ters lojistik tedarikçilerin performanslarını COCOSO ve Tereddütlü Bulanık Kümeler yöntemleri ile hesaplayarak söz konusu hesaba yönelik bir metodoloji önermişlerdir. Araştırmada oluşturulan metodolojinin özellikle belirsiz ve tutarsız bilgiler ve nitel veriler ile karşılaşıldığında uygun bir ölçme performansı sergilediği sonucuna ulaşılmıştır. Torkayesh ve diğ. (2021) BWM ve LBWA tabanlı COSOSO yöntemi ile OECD grubunda olan ve Doğu Avrupa bölgesinde olan ülkelerin sağlık performanslarını belirlemişlerdir. Araştırma sonucuna göre, Litvanya, Slovakya, Slovenya, Polonya ve Estonya ülkelerinin diğer ülkelere kıyasla sağlık performanslarının daha iyi durumda olduğu bulgusuna ulaşılmıştır.

Literatür incelendiğinde bilgi ile ilgili pek çok araştırmaya rastlamak mümkündür. Yine literatür incelendiğinde ülkelerin bilgi performanslarının herhangi bir ÇKKV yöntemi ile ölçen bir çalışmaya rastlanılmamıştır. Buna göre, ülkelerin bilgi performanslarının ölçülmesinin önemi kapsamında ülkelerin bilgi kapasitelerini araştıran çalışmalara gereksinim duyulmaktadır. Bunların dışında sadece yabancı literatürde COCOSO yöntemi ile ilgili olarak araştırmalar bulunmaktadır. Ayrıca COCOSO yöntemi ile ilgili çalışmalar, diğer ÇKKV yöntemi ile ilgili olan çalışmalara kıyasla literatürde daha azdır. Buna göre COCOSO yönteminin karar alternatiflerinin performanslarının belirlenmesinde yüksek bir kararlılık, sağlamlık ve güvenirliliğe sahip olduğundan karar alternatiflerinin performans 
ölçümlerinde daha çok COCOSO ile ilgili araştırmaların yapılması gerektiği değerlendirilmiştir.

\section{YÖNTEM}

\subsection{Araştırmanın Amacı, Verilerin Analizi ve Veri Seti}

Araştırmanın birinci amac1, G7 grubu ülkelerinin COCOSO yöntemi ile bilgi performanslarını tespit etmektir. Araştırmanın ikinci amacı ise GKI ve COSOSO yöntemlerinin diğer ÇKKV yöntemleri ile olan uyum durumunu belirlemektir. Araştırmanın veri setini 2020 yılı için G7 grubu ülkelerin GKI raporunda bulunan bileşen değerleri oluşturmuştur. Bu kapsamda söz konusu veri setini oluşturan bileşenler ve araştırmada kolaylık sağlaması açısından bileşenlerin kısaltmaları Tablo 3'de açıklanmıştır.

G7 grubu ülkeleri dünyanın en büyük 7 ekonomisi olan, küresel ekonominin yaklaşık olarak \%64'üne sahiptir (https://tr.wikipedia.org/wiki/G7). Bilgi ile ekonomik güç arasındaki pozitif yönlü ilişkiye istinaden G7 grubu ülkelerin bilgi performanslarındaki gelişme, diğer ülkelerin bilgi edinme konusundaki stratejilerini ve yöntemlerini etkilemektedir. Dolayısıyla G7 grubu ülkelerin bilgi performanslarının ölçülmesi büyük önem arz etmektedir.

\subsection{COCOSO Yöntemi}

COCOSO (Combined Compromise Solution) yöntemi Yazdani vd. (2019) tarafından geliştirilmiştir. Söz konusu bu yöntemde ilk olarak farklı toplama veya birleştirme operatörleri aracılığı ile farklı açlardan karar alternatiflerinin fayda değeri bulunmuştur. Sonrasında ise bir uzlaşma çözümü sağlamak için her bir karar alternatifin fayda değerlerini bir araya getirmek için birleştirme fonksiyonu sağlanır. Bu yöntem ile elde edilen sonuçlar söz konusu yöntemin gelecek çalışmalarda kullanılabileceği ve farklı seçim problemlerinde uygulanabileceğini göstermektedir (Ecer, 2020: 299). Bu kapsamda yöntemin uygulama adımları aşağıda gösterilmiştir (Ecer, 2020: 300-302).

\section{Adım: Normalizasyon İşleminin Sağlanması}

Fayda ve maliyet kriterleri

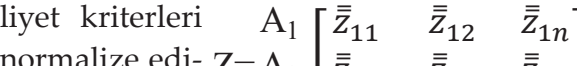
lir. Buna göre, fayda kriterlerin normalizasyonunda eşitlik 3, maliyet kriterlerinin normalizasyonunda ise eşitlik 4 kullanılır.

Fayda kriterleri için normalizas- $\overline{\bar{z}}_{\mathrm{ij}}=\frac{\mathrm{x}_{\mathrm{ij}}-\mathrm{X}_{\mathrm{ij}}^{-}}{\mathrm{x}_{\mathrm{ij}}^{+}-\mathrm{X}_{\mathrm{ij}}^{-}}$ yon:

Maliyet kriterleri için normali-
zasyon:
$\overline{\mathrm{Z}}_{\mathrm{ij}}=\frac{\mathrm{x}_{\mathrm{ij}}^{+}-\mathrm{X}_{\mathrm{ij}}}{\mathrm{x}_{\mathrm{ij}}^{+}-\mathrm{x}_{\mathrm{ij}}^{-}}$

$\mathrm{X}_{\mathrm{ijj}}^{-}{ }_{\text {minimum değeri, }} \mathrm{X}_{\mathrm{ij}}^{+}$maksimum değeri göstermektedir.

\section{Adım: $S_{i}$ ve $P_{i}$ Değerlerinin Hesaplanması} $\begin{aligned} & \mathrm{S}_{\mathrm{i}} \text { değeri gri ilişkisel yaklaşı- } \\ & \text { mına, } \mathrm{P}_{\mathrm{i}} \text { değeri ise WASPAS } \\ & \text { çarpımsal özelliğine istinaden }\end{aligned} \mathrm{S}_{\mathrm{i}}=\sum_{\mathrm{j}=1}^{\mathrm{n}}\left(\mathrm{w}_{\mathrm{j}} \overline{\bar{z}}_{\mathrm{ij}}\right)$ elde edilir.

$$
\mathrm{P}_{\mathrm{i}}=\sum_{\mathrm{j}=1}^{\mathrm{n}}\left(\overline{\overline{\mathrm{Z}}}_{\mathrm{ij}}\right)^{\mathrm{w}_{\mathrm{j}}}
$$

4. Adım: Karar Alternatiflerinin Göreli Performanslarının (Değerlendirme Stratejilerinin) Hesaplanması

Eşitlik 7, eşitlik 8 ve eşitlik 9 yardımıyla değerlendirme stratejileri hazırlanır.

1. Değerlendirme Stratejisi $\quad \xi_{\mathrm{ia}}=\frac{\mathrm{P}_{\mathrm{i}}+\mathrm{S}_{\mathrm{i}}}{\sum_{\mathrm{i}=1}^{\mathrm{m}} \mathrm{P}_{\mathrm{i}}+\mathrm{S}_{\mathrm{i}}}$

\section{Adım: Karar Matrisinin Oluşturul-} masi

$$
\mathrm{C}_{1}, \mathrm{C}_{2} \ldots \mathrm{C}_{\mathrm{n}}
$$

\begin{tabular}{|c|c|c|c|c|}
\hline & $\mathrm{A}_{1}$ & {$\left[\mathrm{x}_{11}\right.$} & $\mathrm{x}_{12}$ & $\mathrm{x}_{1 \mathrm{n}}$ \\
\hline $\mathrm{M}$ alternatif ve $\mathrm{n}$ kriterden oluşan baş- & $\mathrm{X}=\mathrm{A}_{2}$ & $x_{21}$ & $\mathrm{x}_{22}$ & $x_{2 n}$ \\
\hline langıç karar verme matrisi eşitlik 1'de & $\vdots$ & $\vdots$ & $\vdots$ & $\vdots$ \\
\hline gösterilmiştir. & $A_{m}$ & $\mathrm{x}_{\mathrm{m} 1}$ & $\mathrm{x}_{\mathrm{m} 2}$ & $\mathrm{x}_{\mathrm{mn}}$ \\
\hline
\end{tabular}

Tablo. 3. Veri Setini Oluşturan GKI Bileşenleri ve Bileşenlerin Kısaltmaları

\begin{tabular}{|c|c|}
\hline GKI Bileşenleri & KIsaltmalar \\
\hline Üniversite Öncesi Eğitim & GKI1 \\
\hline Teknik ve Mesleki Eğitim Öğretim & GKI2 \\
\hline Yüksek Eğitim & GKI3 \\
\hline Araştırma, Geliştirme ve İnovasyon & GKI5 \\
\hline Bilgi ve İletişim Teknolojisi & GKI6 \\
\hline Ekonomi & GKI7 \\
\hline
\end{tabular}


2. Değerlendirme Stratejisi

$$
\xi_{\mathrm{ib}}=\frac{\mathrm{S}_{\mathrm{i}}}{\min _{\mathrm{i}} \mathrm{S}_{\mathrm{i}}}+\frac{\mathrm{P}_{\mathrm{i}}}{\min _{\mathrm{i}} \mathrm{P}_{\mathrm{i}}}
$$

3. Değerlendirme Stratejisi

$$
\xi_{\mathrm{ic}}=\frac{\lambda\left(\mathrm{S}_{\mathrm{i}}\right)+(1-\lambda)\left(\mathrm{P}_{\mathrm{i}}\right)}{\left(\lambda \mathrm{mak}_{\mathrm{i}} \mathrm{S}_{\mathrm{i}}+(1-\lambda) \mathrm{mak}_{\mathrm{i}} \mathrm{P}_{\mathrm{i}}\right.}, 0 \leq \lambda \leq 1 .
$$

$\lambda$ değeri genellikle 0,5 olarak tercih edilmektedir.

5. Adım: Karar alternatiflerinin Performanslarının Ölçülmesi $\left(\xi_{\mathrm{i}}\right)$

Karar alternatiflerinin performanslarının ölçülmesi eşitlik 7'de, eşitlik 8'de ve eşitlik 9'da belirtilen değerlendirme stratejileri üzerinden eşitlik 10 ile hesaplanır.

$$
\xi_{\mathrm{i}}=\left(\xi_{\mathrm{ia}} \cdot \xi_{\mathrm{ib}} \cdot \xi_{\mathrm{ic}}\right)^{1 / 3}+\frac{\left(\xi_{\mathrm{ia}} \cdot \xi_{\mathrm{ib}} \cdot \xi_{\mathrm{ic}}\right)}{3}
$$

Karar alternatifleri $\left(\xi_{\mathrm{i}}\right)$ değerlerine göre büyükten küçüğe doğru sıralanır. En büyük $\left(\xi_{\mathrm{i}}\right)$ değerine sahip olan karar alternatifi aynı zamanda en iyi performansa sahip olan karar alternatifidir.

\section{BULGULAR}

COCOSO yöntemi kapsamında birinci adımda eşitlik 1 ile karar matrisi oluşturulmuştur. Söz konusu karar matrisi Tablo 4'de gösterilmiştir.

COSOSO yönteminin ikinci aşmasında ise eşitlik 2 ve eşitlik 3 ile fayda kriterlerinin normalizasyon işlemi sağlanmıştır. Buna göre fayda kriterlerin normalize değerleri Tablo 5'de sunulmuştur.

Söz konusu yöntemin üçüncü aşamasında gri ilişkisel yaklaşımı çerçevesinde ülkelerin eşitlik 4 ile $S_{i}$, WASPAS çarpımsal özelliğine dayanılarak eşitlik 5 ile $\mathrm{P}_{\mathrm{i}}$ değerleri hesaplanmıştır. Bu kapsamda ülkelere ait hesaplanan $S_{i}$ ve $P_{i}$ değerleri Tablo 6'da gösterilmiştir.

Tablo 4. Karar Matrisi

\begin{tabular}{|c|c|c|c|c|c|c|c|c|}
\hline Ülkeler & GKI & GKI1 & GKI2 & GKI3 & GKI4 & GKI5 & GKI6 & GKI7 \\
\hline ABD & 71,1 & 63,2 & 92,3 & 57,8 & 64,3 & 86,5 & 61,1 & 73,5 \\
\hline Almanya & 66,2 & 63 & 64,3 & 60,2 & 61,2 & 81,5 & 58,6 & 78,9 \\
\hline İngiltere & 68,1 & 68,1 & 63,4 & 68,3 & 58,2 & 84,2 & 60,1 & 77,5 \\
\hline Fransa & 64 & 75,4 & 55,1 & 55,4 & 54,6 & 79,4 & 56,2 & 75,9 \\
\hline İtalya & 56,6 & 71,2 & 54,6 & 51,1 & 42 & 66,3 & 44,4 & 71,9 \\
\hline Kanada & 61,1 & 56,6 & 52,8 & 62,8 & 46,5 & 77,7 & 58,5 & 78,4 \\
\hline Japonya & 66,2 & 75,5 & 61 & 50,5 & 63,2 & 83,2 & 56,2 & 77,5 \\
\hline
\end{tabular}

Tablo 5. Kriterlerin Normalize Değerleri

\begin{tabular}{|c|c|c|c|c|c|c|c|c|}
\hline \multicolumn{9}{|c|}{$S_{i}$ Değerleri } \\
\hline Ülkeler & GKI1 & GKI2 & GKI3 & GKI4 & GKI5 & GKI6 & GKI7 & \multirow{2}{*}{$\mathbf{S}_{\mathrm{i}}$} \\
\hline $\mathbf{w}$ & 0,15 & 0,15 & 0,15 & 0,15 & 0,15 & 0,15 & 0,10 & \\
\hline ABD & 0,052381 & 0,15 & 0,0615169 & 0,15 & 0,15 & 0,15 & 0,0228571 & 0,7367549 \\
\hline Almanya & 21,401058 & 92,3 & 31,497753 & 58,233962 & 73,452514 & 55,26242 & 73,5 & 405,64771 \\
\hline İngiltere & 38,333333 & 64,3 & 60,2 & 46,766038 & 81,5 & 58,6 & 67,975385 & 417,67476 \\
\hline Fransa & 67,739683 & 17,782927 & 27,208943 & 34,590566 & 65,267456 & 50,296454 & 47,692308 & 310,57834 \\
\hline İtalya & 71,085741 & 49,222667 & 45,010816 & 35,990354 & 63,075669 & 42,418783 & 69,588871 & 376,3929 \\
\hline Kanada & 53,296123 & 47,138 & 51,1 & 30,74055 & 61,871994 & 44,4 & 71,9 & 360,44667 \\
\hline Japonya & 56,6 & 52,8 & 62,8 & 46,5 & 77,7 & 58,5 & 78,4 & 433,3 \\
\hline \multirow{2}{*}{\multicolumn{8}{|c|}{ Toplam $\mathrm{S}_{\mathrm{i}}$}} & 2305 \\
\hline & & & & & & & & \multirow{2}{*}{$\mathbf{P}_{\mathbf{i}}$} \\
\hline $\mathbf{w}$ & 0,15 & 0,15 & 0,15 & 0,15 & 0,15 & 0,15 & 0,10 & \\
\hline ABD & 0,8540087 & 1 & 0,8748537 & 1 & 1 & 1 & 0,8627842 & 6,5916467 \\
\hline Almanya & $1,90 \mathrm{E}-30$ & 1 & $5,77 \mathrm{E}-16$ & 0,0017095 & $7,21 \mathrm{E}-07$ & 0,0021645 & 1 & 2,0038747 \\
\hline İngiltere & $2,55 \mathrm{E}-14$ & 1 & 1 & 7,09E-08 & 1 & 1 & $7,82 \mathrm{E}-06$ & 4,0000079 \\
\hline Fransa & 0,696788 & $9,95 \mathrm{E}-36$ & $5,01 \mathrm{E}-28$ & $7,06 \mathrm{E}-14$ & $4,85 \mathrm{E}-10$ & $2,25 \mathrm{E}-05$ & $4,56 \mathrm{E}-17$ & 0,6968105 \\
\hline İtalya & 0,0117652 & 0,0019992 & $1,01 \mathrm{E}-05$ & $1,31 \mathrm{E}-10$ & $1,16 \mathrm{E}-08$ & $1,36 \mathrm{E}-07$ & 0,0013754 & 0,01515 \\
\hline Kanada & $1,11 \mathrm{E}-09$ & 0,0003276 & 1 & $2,03 \mathrm{E}-06$ & 0,0102262 & 1 & 1 & 3,0105558 \\
\hline Japonya & 1 & 1 & 1 & 1 & 1 & 1 & 1 & 7 \\
\hline & & & & & & & Topla & 23,318 \\
\hline
\end{tabular}

\begin{tabular}{|c|c|c|c|c|c|c|c|}
\hline Ülkeler & GKI1 & GKI2 & GKI3 & GKI4 & GKI5 & GKI6 & GKI7 \\
\hline Yönler & Maks. & Maks. & Maks. & Maks. & Maks. & Maks. & Maks. \\
\hline ABD & 0,3492063 & 1 & 0,4101124 & 1 & 1 & 1 & 0,2285714 \\
\hline Almanya & 0,3386243 & 1 & 0,5449438 & 0,9056604 & 0,84916201 & 0,9044586 & 1 \\
\hline İngiltere & 0,6084656 & 1 & 1 & 0,7641509 & 1 & 1 & 0,8615385 \\
\hline Fransa & 0,994709 & 0,2804878 & 0,398374 & 0,5943396 & 0,77514793 & 0,8368794 & 0,6153846 \\
\hline İtalya & 0,9427817 & 0,8933333 & 0,8124696 & 0,659164 & 0,79440389 & 0,7547826 & 0,9168494 \\
\hline Kanada & 0,7485411 & 0,8633333 & 1 & 0,7319179 & 0,93321258 & 1 & 1 \\
\hline Japonya & 1 & 1 & 1 & 1 & 1 & 1 & 1 \\
\hline
\end{tabular}

Tablo 6. Ülkelerin $S_{i}$ ve $P_{i}$ Değerleri 
Tablo 7. Ülkelerin Göreli ve Nesnel Performans Değerleri

\begin{tabular}{|c|c|c|c|c|c|}
\hline & \multicolumn{3}{|c|}{ Göreli Performans Değerleri } & \multirow{2}{*}{$\xi_{i}$} & \multirow{2}{*}{ Siralama } \\
\hline Ülkeler & $\left(\xi_{i a}\right)$ & $\left(\xi_{i b}\right)$ & $\left(\xi_{i c}\right)$ & & \\
\hline ABD & 0,00314781 & 436,0927714 & 3,516912997 & 148,23 & 1 \\
\hline Almanya & 0,17510091 & 133,5752381 & 11,83589522 & 55,047 & 5 \\
\hline İngiltere & 0,181124367 & 265,3721059 & 11,84197961 & 100,75 & 2 \\
\hline Fransa & 0,13370379 & 46,99415437 & 11,79407927 & 23,840 & 7 \\
\hline İtalya & 0,161680697 & 58,10149818 & 11,82233923 & 28,168 & 6 \\
\hline Kanada & 0,156117855 & 180,8748537 & 11,81672011 & 71,218 & 4 \\
\hline Japonya & 0,189124571 & 217,2310853 & 11,85006076 & 84,290 & 3 \\
\hline \multicolumn{4}{|c|}{ Ortalama } & 73,078 & \\
\hline
\end{tabular}

COCOSO yönteminin dördüncü adımında eşitlik 6 $\left(\xi_{i a}\right)$, eşitlik $7\left(\xi_{i b}\right)$ ve eşitlik $8\left(\xi_{i c}\right)$ ile ülkelerin göreli performans değerleri ölçülmüştür. Yöntemin son adımında ise ülkelerin nesnel performans değerleri $\left(\xi_{i}\right)$ eşitlik 9 ile belirlenmiştir. Buna göre, ülkelerin ölçülen göreli performans değerleri ile nesnel performans değerleri Tablo 7'de belirtilmiştir.

Tablo 7 incelendiğinde, ülkelerin bilgi performans değerleri $\operatorname{ABD}\left(\xi_{i-A B D}=148,23\right)$, İngiltere $\left(\xi_{i-\text { İngiltere }}\right.$ $=100,75)$, Japonya $\left(\xi_{i \text {-Japonya }}=84,290\right), \quad K a n a d a \quad($ $\left.\xi_{i \text {-Kanada }}=71,218\right)$, Almanya $\left(\xi_{i-A l m a n y a}=55,047\right)$ İtalya $\left(\xi_{i-\text { Italya }}=28,168\right)$ ve Fransa $\left(\xi_{i-F r a n s a}=23,840\right)$ olarak sıralanmıştır. Tablo 7 değerlendirildiğinde, ülkelerin bilgi performanslarının çok olması açısından ABD'nin diğer ülkeler açısından belirgin farklılıkları bulunmaktadır. Yine ülkelerin bilgi performansları az olması açısından ise özellikle İtalya ve Fransa'nın diğer ülkeler arasında belirgin farklılıkları mevcuttur. Tablo 7'ye istinaden ülkelerin ayrıca ortalama bilgi performans değeri ölçülmüştür. Bu ölçüme göre, Fransa, İtalya, Almanya ve Kanada ortalama bilgi performans değerinin altında değer almıştır. Buna karşın ABD ve İngiltere bilgi performans değerleri ortalama değerin üstündedir.

Araştırmada ayrıca bazı ÇKKV tekniklerine göre ülkelerin bilgi performansları aynı değişkenler (GKI değişkenleri) üzerinden ölçülerek tespit edilen değerler arasında ilişki katsayıları tüm yöntemlere göre değerler normal dağılım gösterdiği için Pearson korelasyon katsayısı ile ölçülmüştür. Buna istinaden GKI, COCOSO ve diğer ÇKKV yöntemleri arasında hesaplanan ilişki değerleri Tablo 8'de açıklanmıştır.

Tablo 8'de GKI'nın diğer ÇKKV yöntemleri ile belirlenen ülkelerin bilgi performans değerleri ile anlamlı, pozitif yönde ve yüksek düzeyde ilişki tespit edilmiştir. Bu durum, GKI'nın belirtilen tüm ÇKKV yöntem- leri ile uyumlu olduğu ve buna bağlı olarak GKI'nın Tablo 8'de belirtilen tüm ÇKKV yöntemleri ile genel anlamda açılanabileceğini göstermektedir. Bunun yanında COCOSO yöntemi kapsamında ölçülen ülkelerin bilgi performans değerleri ile EDAS ve GİA yöntemleri kapsamında hesaplanan ülkelerin bilgi performans değerleri arasındaki ilişkiler pozitif yönlü, anlamlı ve çok yüksek düzeydedir.

\section{SONUÇ VE TARTIŞMA}

Ülkelerin bilgi performanslarının ölçülmesiyle ülkeler mevcut ve sonraki dönemler için gerekli bilgi edinimini sağlamak için stratejiler, planlar ve faaliyetler gerçekleştirmektedirler. Buna bağlı olarak ülkelerin bilgi performanslarının ölçümü büyük önem kazanmakta olup, ülkeler her zaman kendilerinin bilgi performanslarını ölçen metriklere gereksinim duymaktadırlar. Bu kapsamda araştırmada, bilgi performansının ülkelerin ekonomileriyle doğrudan ilişkisi bulunmasından dolayı dünyanın en büyük ekonomileri olan ve bilgi konusunda yapmış oldukları faaliyetleriyle diğer ülkelerin bilgi stratejilerini etkileyen G7 gurubu ülkelerin bilgi performansları 2020 GKI raporunda GKI bileşenlerine ait değerler üzerinden COCOSO yöntemi ile belirlenmiştir. Diğer amaç ise GKI ile COCOSO yönteminin birbirleri ve bazı ÇKKV yöntemler ile olan uyum değeri ölçmektir.

Bulgulara göre, ülkelerin bilgi performansları COCOSO yöntemi kapsamında ABD, İngiltere, Japonya, Kanada, Almanya, İtalya ve Fransa olarak sıralanmıştır. Ayrıca bulgular kapsamında ABD ve İtalya ülkelerinin ortalama bilgi performans değerinin üstünde olduğu tespit edilmiştir. Buna karşın Japonya, Kanada, Almanya, İtalya ve Fransa ülkelerinin bilgi performans değerlerinin ortalama değerin altında olduğu gözlenmiştir. Bunun yanında bilgi performansın yüksek olması açısından ABD'nin diğer ülkeler arasında farklılıkların fazla olduğu belirlenmiştir.

Tablo 8. Yöntemler Arası Pearson Korelasyon Değerleri

\begin{tabular}{|c|c|c|c|c|c|}
\hline Yöntemler & 1 & 2 & 3 & 4 & 5 \\
\hline GKI (1) & 1 & & & & \\
\hline COCOSO (2) &, $784^{*}$ & 1 & & & \\
\hline EDAS (3) &, $885^{* *}$ &, $972^{* *}$ & 1 & & \\
\hline TOPSIS (4) &, $838^{*}$ & 0,608 &, $858^{*}$ & 1 & \\
\hline GİA (15) &, $885^{* *}$ &, $951^{* *}$ &, $828^{*}$ & $953^{* *}$ & 1 \\
\hline
\end{tabular}


Araştırmada ayrıca ülkelerin bilgi performans (GKI) ve COCOSO yöntemi kapsamında hesaplanan ülkelerin bilgi performans değerleri, diğer ÇKKV teknikleri olan EDAS, TOPSIS, GİA yöntemleri ile tespit edilen ülkelerin bilgi performans değerleri arasındaki Pearson ilişki katsayıları ölçülmüştür. Bulgulara göre, GKI'nın ve COCOSO yönteminin birbirleri ve tüm yöntemler ile anlamlı, pozitif yönde ve yüksek seviyede ilişkiler gözlenmiştir. Böylelikle GKI'nın ve COCOSO yönteminin birbirleri ve diğer ÇKKV yöntemleri ile uyum içinde olduğu ve söz konusu yöntemler ile açıklanabileceği sonucuna ulaşılmıştır.

Literatür değerlendirildiğinde, bu araştırma ülkelerin bilgi performanslarının herhangi bir ÇKKV yöntemi ile ölçülmemesi açısından sadece yöntem kapsamında Peng ve diğ. (2019) araştırmasına benzerlik göstermektedir. Peng ve diğ. (2019) araştırmasında 5G endüstri işletmelerin performanslarını COCOSO ve TOPSIS yöntemi ile ölçmüşler ve COSOSO yöntemi ile TOPSIS yönteminin birbirleri ile uyum içinde olduklarını gözlemlemişlerdir. Bu araştırmada da ülkelerin bilgi performans değerleri COCOSO ve TOPSIS yöntemi birbirleri ile uyum sağlamıştır.

Öneriler kapsamında ortalama bilgi performans değerinin altında kalan Japonya, Kanada, Almanya, İtalya ve Fransa ülkelerinin birbirleri ve diğer G7 ülkeleri ile bilgi açısından uyum içinde olmaları için bilgi bileşenine önem vererek söz konusu bileşenlerin birbirlerini pozitif yönde sağlayacak, oluşturacak veya birbirlerine onarıcı etkisi olan faaliyetler gerçekleştirmelidirler. Böylelikle G7 ülkelerinin bilgi konusunda uyum ile dünya ekonomisi, bilginin sinerjik bir yapı alabilmesinden dolayı gelişebilecektir. Böylelikle G7 ülkelerinin dünya üzerinde sağladığı bu ekonomik büyüme diğer ülkeleri etkileyebilecek ve diğer ülkelerin G7 ülkelerinin dünya ekonomik büyüme için yaptıkları faaliyetlerden yararlanabileceklerdir. Yöntem kapsamında ise gelecek çalışmalarda ülkelerin bilgi performanslarını ölçen GKI bileşenlerinin sayısı artırılabilir ya da her ülkeye özgü bilgi performans bileşenleri oluşturulabilir. Buna bağlı olarak ülkelerin bilgi performanslarına daha gerçekçi yaklaşımlar ile ölçülebilir. Bunların dışında dünya ülkelerine göre bilgi bileşenlerinin birbirlerini tamamlama seviyeleri korelasyon veya etki analizleri ile hesaplanabilir. Buna göre, hangi bilgi bileşenin diğer bileşenleri sağlama veya sağlamama dereceleri ölçülerek ülkelerin bilgi performanslarını artırmaları için hangi bileşen(ler)e önem verilmesi gerektiğinin tespiti yapılabilecektir.

\section{KAYNAKÇA}

ABU, R., REED, M., \& JARDINE, T. (2019). Using Two-Eyed Seeing to Bridge Western Science and Indigenous Knowledge Systems and Understand Long-Term Change in the Saskatchewan River Delta, Canada. International Journal of Water Resources Development, 1-20.

ABU, R., REED, M., \& JARDINE, T. (2019). Using Two-Eyed Seeing to Bridge Western Science and Indigenous Knowledge Systems and Understand LongTerm Change in the Saskatchewan River Delta, Canada. International Journal of Water Resources Development, $1-20$.

ADIGÜZEL, A. (2011). Bilgi Okuryazarlığı Ölçeğinin Geliştirilmesi. Dicle Üniversitesi Ziya Gökalp Eğitim Fakültesi Dergisi, 17, 15-28.

ALAM, M., PARVEEN, R., KHAN, I. R., \& HAMDARD, J. (2020). Role of Information Technology in Covid-19 Prevention. International Journal of Business Education and Management Studies, 5(1), 65-78.

ALSAYED, A., \& BILGRAMI, A. (2017). Information Technology and Information Technology and Culture: Problems and Remedies. International Journal of Latest Research in Science and Technology, 6(1), 22-27.

ANAMERİÇ, H. (2005). Bilgi Merkezlerinin Yönetiminde Bilgi Sistemlerinin Rolü. Bilgi Dünyas», 6(1), 15-35.

BAGAL, D. K., GIRI, A., PATTANAIK, A. K., JEET, S., BARUA, A., \& PANDA, S. N. (2021). Optimization of Characteristics in Resistance Spot Welding for Dissimilar Materials Utilizing Advanced Hybrid Taguchi Method Coupled CoCoSo EDAS and WASPAS Method. Darussalam: AIJR Publisher.

BARUA, A., JEET, S., BAGAL, D., SATAPATHY, P., \& AGRAWAL, P. (2019). Evaluation of Mechanical Behavior of Hybrid Natural Fiber Reinforced Nano Sic Particles Composite using Hybrid Taguchi-Cocoso Method. International Journal of Innovative Technology and Exploring Engineering, 8(10), 3341-3344.

BASTALICH, W. (2010). Knowledge Economy and Research Innovation. Studies in Higher Education, 35(7), 845-857.

BHATT, G. D. (2001). Knowledge management in organizations: examining the interaction between technologies, techniques, and people. Journal of Knowledge Management, 5(1), 68-75.

BISWAS, S. (2020). Measuring Performance of Healthcare Supply Chains in India: A Comparative Analysis of Multi Criteria Decision Making Methods. Decision Making: Applications in Management and Engineering, 3(2), 162-189. 
BRADY, F. (2021). Training Peer Teachers to Teach First Year Graduate Level Information. The Journal of Academic Librarianship(47), 1-12.

BRATIANU, C., STANESCU, D., \& MOCANU, R. (2021). Exploring the Knowledge Management Impact on Business Education. Sustainability, 13, 1-16.

BUCKLAND, M. K. (1991, June). Information as Thing. Journal Of The American Society For Information Science, 42(5), 351-360.

CHATTERJEE, S., MOODY, G., LOWRY, P. B., CHAKRABORTY, S., \& HARDIN, A. (2020). The Nonlinear Influence of Harmonious Information Technology Affordance on Organizational Innovation. Information Systems Journal , 1-9.

COUDHARY, V., \& MISHRA, A. (2021). Analyzing the Critical Success Enablers of Industry 4.0 Using Hybrid-Fuzzy AHP-COCOSO Method. Journal of Industrial Integration, 6(22), 1-22.

DAUTH, C., KRUPPE, T., \& STEPHAN, G. (2018). Zur Qualifizierungsoffensive "Wissen und Sicherheit für den Wandel" des Bundesministeriums für Arbeit und Soziales. Ausgewählte Beratungsergebnisse des Instituts für Arbeitsmarkt- und Berufsforschung(6), 1-11.

DAVENPORT, T. H., \& PRUSAK, L. (2001). Working Knowledege How Organizastions Manege What They Know. Boston, Massachusetts, United States of America: Harward Business School Press.

DEMIRHAN, D. (2002). İşletmelerde Stratejik Bilgi Sistemleri Yönetimi ve Rekabet Üstünlüğünün Eldev Edilmesindeki Rolü. Ege Akademik Bakış, 2(2), 117-124.

DESOUZA, K. (2006). Knowledge Security: An Interesting Research Space. Journal of Information Science and Technology, 3(1), 1-7.

DI VAIO, A., PALLADINO, R., PEZZI, A., \& KALISZ, D. (2021). The role of digital innovation in knowledge management systems: A Systematic Literature Review. Journal of Business Research, 123, 220-231.

DOZ, Y., SANTOS, J., \& WILLIAMSON, P. (2001). From Global to Metanational How Companies Win in the Knowledge Economy. Massachusetts: Harvard Business School Publishing.

DURNA, U., \& DEMİREL, Y. (2008). Bilgi Yönetiminde Bilgiyi Anlamak. Erciyes Üniversitesi İktisadi ve İdari Bilimler Fakültesi Dergisi, 129-156.

DURNALI, M., \& LİMON, İ. (2020). Bilgi Yönetimi Eğilimi Ölçeğinin Türkiye Kültürüne Uyarlanması:Geçerlik ve Güvenirlik Çalışması. Kastamonu Ĕ̆̈itim Dergisi, 28(1), 95-106.

ECER, F. (2020). Çok Kriterli Karar Verme. Ankara: Seçkin Yayıncılık.
ECER, F., \& PAMUCAR, D. (2020). Sustainable Supplier Selection: A Novel Integrated Fuzzy Best Worst Method (F-BWM) and Fuzzy CoCoSo with Bonferroni (CoCoSo'B) Multi-Criteria Model. Journal of Cleaner Production, 266, 1-18.

ETZKOWITZ, H., RANGA, M., \& DZISAH, J. (2012). Whither the university? The Novum Trivium and the Transition from Industrial to Knowledge Society. Social Science Information, 51(2), s. 143-164.

EZER, M., \& KIRAL, E. (2018). Türkiye'de Bilgi Toplumunun Gelişimi: Kişisel İnternet Kullanım Amaçları Üzerine Bir Uygulama. Çukurova Üniversitesi Sosyal Bilimler Enstitüsü Dergisi, 27(1), 207-222.

FOKOU, P., \& FOKOUO, R. (2020). Exploring the Indigenous Knowledge Systems to Respond to Coronavirus Infection 2019 in Cameroon. Ethnobotany Research $\mathcal{E}$ Applications, 20(37), 1-27.

GREEN, A. (2005). Models of Lifelong Learning and the 'Knowledge Society'. Compare, 36(3), 307-325.

GÜNER, O. (2020). Bilgi Toplumu Göstergeleri Bağlamında Avrupa Birliği Ülkeleri ve Türkiye'ye Dair Bir Değerlendirme. Isşletme Ekonomi ve Yönetim Araştırmaları Dergisi(2), 121-143.

HADAD, S. (2017). Knowledge Economy: Characteristics and Dimensions. Management Dynamics in the Knowledge Economy, 5(2), 203-225.

HARIHARAN, M. R., \& KHENEJA, M. (2003). E-Knowledge Management Framework for Goverment Organizations. Information System Management, 38-48.

HOCK-DOEPGEN, M., CLAUSS, T., KRAUS, S., \& CHENG, C.-F. (2021). Knowledge Management Capabilities and Organizational Risk-taking for Business Model Innovation in SMEs. Journal of Business Research, 130, 683-697.

HÖHNE, T. (2004). Pädagogik der Wissensgesellschaft. Bielefel: Transcript Verlag.

INGRAM, J. (2018). Agricultural Transition: Niche and Regime Knowledge Systems' Boundary Dynamics. Environmental Innovation and Societal Transitions, 26, 117-135.

IŞIK, N., \& KILINÇ, E. C. (2013). Bilgi Ekonomisi ve İktisadi Büyüme: OECD Ülkeleri Üzerine Bir Uygulama. Akdeniz İİ.B.F. Dergisi(26), 21-54.

JALALI, M., LANDMAN, A., \& GORDON, W. (2021). Telemedicine, Privacy, and Information Security in the Age of COVID-19. Journal of the American Medical Informatics Association, 28(3), 671-672.

JONES-JANG, S., MORTENSEN, T., \& LIU, J. (2019). Does Media Literacy Help Identification of Fake 
News? Information Literacy Helps, but Other Literacies Don't. American Behavioral Scientist, 1-18.

KAYA, Ş., ŞİMŞEK, G., \& OKUL, T. (2020). Lisans Düzeyinde Turizm Eğitimi Alan Öğrencilerin Girişimcilik Eğilimi ve Bilgi Teknolojileri Yeterliliği İlişkisi: Aydın Adnan Menderes Üniversitesi Örneği. Journal of Tourism and Gastronomy Studies, 8(1), 257-277.

KELEŞ, B., \& OVA, G. (2020). Gida Tedarik Zinciri Yönetiminde Bilgi Teknolojileri Kullanımı. Adnan Menderes Üniversitesi Ziraat Fakültesi Dergisi, 17(1), 137-143.

KILIÇ, B., YALÇIN, N., \& KILIÇ, E. (2021). Hukuk Bürolarinda Bilgi Güvenliğinin Arttırılmasında Model Önerileri. TBB Dergisi(152), 335-365.

KURBANOĞLU, S. (2010). Bilgi Okuryazarlığı: Kavramsal Bir Analiz. Türk Kütüphaneciliği, 24(4), 723-747.

MACKEY, T., \& JACOBSON, T. E. (2011). Reframing Information Literacy as a Metaliteracy. College $\mathcal{E}$ Research Libraries, 72(1), 62-76.

MARTIN, A., \& RADER, H. (2004). Information and IT Literacy. Library Review(53), 465-466.

MISHRA, A. R., RANI P., KRISHANKUMAR, R., ZAVADSKAS, E. K., CAVALLARO, F., \& RAVICHANDRAN, K. S. (2021). A Hesitant Fuzzy Combined Compromise Solution Framework-Based on Discrimination Measure for Ranking Sustainable Third-Party Reverse Logistic Providers. Sustainability, 13, 1-24.

NAVEED, M. A. (2021). Information Literacy Self-efficacy of Scientists. Information Research 26(1), 26(1), $1-23$.

OLIMPO, G. (2010). Società della Conoscenza, Educazione, Tecnologia. TD-Tecnologie Didattiche. 50, 4-16.

ÖZER, G., CİĞERIM, E., \& GÖK, M. Ş. (2020). Entelektüel Sermaye ve Bilgi Yönetimi Stratejilerinin Firma Performansina Etkisi. BMIJ, 8(5), 4611-4645.

PENG, X., ZHANG, X., \& LUO, Z. (2020). Pythagorean Fuzzy MCDM Method Based on CoCoSo and CRITIC with Score Function for 5G Industry Evaluation. Artificial Intelligence Review, 53, 3813-3847.

PETERS, M. A. (2003). Classical Political Economy and the Role of Universities in the New Knowledge Economy. Globalisation, Societies and Education, 1(2), 153168.

POWELL, W., \& SNELLMAN, K. (2004). The Knowledge Economy. Annu. Rev. Sociol, 30, 199-220.

SHOKRI-GHASABEH, M., \& CHILESHE, N. (2014). Knowledge Management Barriers to Capturing Lessons Learned from Australian Construction Contractors Perspective. Construction Innovation, 14(1), 108134.

TALAN, T., \& AKTÜRK, C. (2021). Ortaöğretim Öğ- rencilerinin Dijital Okuryazarlık ve Bilgi Güvenliği Farkındalığ1 Seviyelerinin İncelenmesi. Kahramanmaraş Sütçü İmam Üniversitesi Sosyal Bilimler Dergisi, 18(1), 158-180.

TANG, Z., MILLER, A., ZHOU, Z., \& WARKENTIN, M. (2021). Does Government Social Media Promote Users' Information Security Behavior towards COVID-19 Scams? Cultivation Effects and Protective Motivations. Government Information Quarterly, 38, 1-11.

TENGÖ, M., BRONDIZIO, E., ELMQVIST, T., MALMER, P., \& SPIERENBURG, M. (2014). Connecting Diverse Knowledge Systems for Enhanced Ecosystem Governance: The Multiple Evidence Base Approach. AMBIO, 43, 579-591.

TIMMOR, M., \& YÜZBAŞİ KÜNÇ, G. (2021). Ekonomik Gelişmişliği Etkileyen Bilgi Ekonomisi Değişkenlerinin Veri Madenciliği ile Belirlenmesi. Optimum Ekonomi ve Yönetim Bilimleri Dergisi, 2021, 8(1), 1-18.

TORKAYESH, A. E., PAMUCAR, D., ECER, F., \& CHATTERJEE, P. (2021). An integrated BWM-LBWA-CoCoSo Framework for Evaluation of Healthcare Sectors in Eastern Europe. Socio-Economic Planning Sciences, 1-12.

UBISI, N. R., KOLANISI, U., \& JIRI, O. (2019). Comparative Review of Indigenous Knowledge Systems and Modern Climate Science. Journal of Conflict and Social Transformation, 8(2), 53-73.

UGLI, K. A. (2020). The Role and Role of Digital Economy and Information Technology in the Agricultural Sector. International Journal on Integrated Education, 3(2), 42-44.

UNDP, \& MBRF. (2017). Global Knowledge Index. Dubai: Al Ghurair Printing and Publishing.

UNDP, \& MBRF. (2018). Global Knowledge Index. Dubai: Al Ghurair Printing and Publishing.

UNDP, \& MBRF. (2019). Global Knowledge Index. Dubai: Al Ghurair Printing and Publishing.

UNDP, \& MBRF. (2020). Global Knowledge Index. Dubai: Al Ghurair Printing and Publishing.

WAHAB, S., BAHAR, N., \& RADZİ, N. (2021). An Inquiry on Knowledge Management in Third-Party Logistics Companies. Int. J. Business Innovation and Research, 24(1), 124-146.

WU, Y., TAYI, G. K., FENG, G., \& FUNG, R. (2021). Managing Information Security Outsourcing in a Dynamic Cooperation Environment. Journal of the Association for Information Systems, 22(3), 827-850.

YAZDANI, M., ZARATE, P., ZAVADSKAS, E., \& TURSKIS, Z. (2018). A Combined Compromise Solution (CoCoSo) Method for Multi-Criteria Decision-Ma- 
king Problems. Management Decision, 1-19.

YE, Q., MA, J., \& BA; , H. (2020). Using Information Technology to Manage the COVID-19 Pandemic: Development of a Technical Framework Based on Practical Experience in China. JMIR Med Inform 2020, 8(6), 1-9.

ZOLFANI, S. H., CHATTERJEE, P., \& YAZDANI, M. (2019). A Structured Framework for Sustainable Supplier Selection Using A Combined BWM-COCOSO Model. International Scientific Conference CONTEMPORARY ISSUES IN BUSINESS, MANAGEMENT AND ECONOMICS ENGINEERING'2019. Vilnius: Vilnius Tech, 797-804.

İnternet Kaynakları

https://tr.wikipedia.org/wiki/G7 